\title{
A Comparative Study of Immigrant Children Starting Childcare
}

\author{
Karen Guo \\ Deakin University
}

\begin{abstract}
This comparative study investigated the experiences of starting childcare of three immigrant children in three different learning environments in New Zealand. The notion of learning environment was explored as a way of thinking about how different people, places, and approaches to learning have interacted to create a particular site for the children's beginning experiences in early childhood settings. The study sheds light on multiple perceptions and experiences with regard to immigrant children and their learning. Child observations, child interviews, and teacher and parent interviews were conducted in each child's setting. Findings suggest that early childhood environments played a critical role in supporting immigrant children's transition from homes to early childhood centres if they were informed by the principles of familiarity, care, and collaboration. Immigrant children's motivation to drive their own learning also provoked reflection on education both in New Zealand and other immigrant-receiving countries such as Canada, the United States, and Australia.
\end{abstract}

Te Whāriki, the New Zealand early childhood curriculum (Ministry of Education New Zealand, 1996), has put five learning outcomes - namely well-being, belonging, contribution, communication, and exploration - on the reform agenda in children's learning and development. The learning environment is identified as an essential instrument in achieving these learning outcomes. After more than two decades of reform, many teaching and learning strategies have been developed to promote the ideas in $\mathrm{Te}$ Whāriki (Gunn, 2015; Nuttall, 2013). In this context, it is timely to explore children's learning in the early childhood environments in New Zealand. My aim in this paper is to make a special contribution in this regard by exploring early childhood environments in 
relation to immigrant children's experiences and to the reconceptualized understandings of children's learning evident in the curriculum vision of learning environments.

Specifically, the paper examines the starting experiences of immigrant children in early childhood settings in New Zealand, exploring how they were progressing toward the five outcomes in Te Whäriki (see Table 1), and discussing how the early childhood environments supported children's learning in ways that contributed to children's "wellbeing and trust, belonging and purposeful activity, contributing and collaborating, communicating and representing, and exploring and guided participation" (Ministry of Education New Zealand, 1996, p. 45). This is an important topic given the increasing racial and cultural diversity in early childhood services (Office of Ethnic Communities New Zealand, 2016), and the fact that Te Whāriki closely guides early childhood teaching and learning.

Table 1

Te Whāriki Vision of Children's Learning*

\begin{tabular}{ll}
\hline \multicolumn{1}{c}{ Learning Outcomes } & \multicolumn{1}{c}{ Definitions } \\
\hline Well-being and trust & $\begin{array}{l}\text { Acquiring "a sense of self-worth, identity, confidence, and } \\
\text { enjoyment and develop[ing] trust that their needs will be } \\
\text { responded to" (p. 46). } \\
\text { "[Gaining] opportunities for social interaction with adults and oth } \\
\text { children and respect[ing] the achievements and aspirations of th } \\
\text { child's family and community" (p. 54). } \\
\text { "Eelonging and } \\
\text { purposeful activity } \\
\text { Contributing and } \\
\text { collaborating }\end{array}$ \\
$\begin{array}{l}\text { understand their own ways of learning and being creative. Active } \\
\text { and interactive learning opportunities that are equitable for all } \\
\text { children" (p. 64). }\end{array}$ \\
$\begin{array}{l}\text { Communicating and } \\
\text { representing }\end{array}$ & $\begin{array}{l}\text { Promoting and protecting "the languages and symbols of their } \\
\text { [children's] own and other cultures" (p. 72). }\end{array}$ \\
$\begin{array}{l}\text { Exploring and guided } \\
\text { participation }\end{array}$ & $\begin{array}{l}\text { [Being involved in] "open-ended exploration and play in an } \\
\text { environment where the consistent, warm relationships help to } \\
\text { connect the child's experiences and where the tasks, activities, } \\
\text { and contexts all have meaning for the child" (p. 82). }\end{array}$
\end{tabular}

* Ministry of Education New Zealand, 1996

The research is grounded on the premise that "the adults, the other children, the physical environment and the resources" (Ministry of Education New Zealand, 1996, p. 11) constitute children's learning environments. The study contrasts the experiences of three different children in three different learning environments. Participants shared similar backgrounds: boys, aged around three, born to immigrant families, speaking limited English, and starting their first childcare experiences. For these reasons, the paper incorporates multiple voices and experiences in understanding participating children's starting experiences in their new environments. It is the purpose of the study to locate the concept of transition with immigrant children within the broader concept of learning environments and more importantly with a perspective that "emphasizes the critical role 
of socially and culturally mediated learning and of reciprocal and responsive relationships for children with people, places and things" (Ministry of Education New Zealand, 1996, p. 9).

\section{Learning and the Learning Environments: Theoretical Perspectives}

The notion of "learning environment" introduced in Te Whāriki is framed within a socio-cultural approach to learning, a view in which social and cultural relationships assume a central role. From a socio-cultural perspective, learning environment can be defined as the most essential aspect of human learning, or in Vygotsky's (1978) terms, a socio-cultural context that focuses on the role of adults or expert peers in supporting children's learning by scaffolding them toward the development of appropriate knowledge and skills within the context.

Learning and development is viewed as the result of guided participation (Rogoff, 2003). Through developing this perspective, Rogoff, another prominent figure of the socio-cultural school of thoughts, argued that when individuals participate in cultural activities, they prepare for involvement with future related activities. Children's learning and development occur in the form of gradually advancing cultural understanding, and are the result of increasing repertories of participation in cultural practices. Guided participation is premised on the belief that children are powerful and active learners, furthermore it considers the efforts of their social partners and the learning environment as integral to the process (Rogoff, 2003).

Another, more elaborate approach to conceptualizing learning environments consists of Leontiev's (1977) activity theory. The activity theory describes learning as a threelevel model of activity that requires a motive, goals of individuals, and the tools at hand. Within this theory, Leontiev sees activities as being mediated by the learning environments in which they are implemented. Leontiev's thinking about activity is of great significance to education in that he establishes activity as the process of learning that "realises a person's actual life in the objective world by which he is surrounded, his social being in all the richness and variety of its forms" (1977, p. 2).

In a more recent writing, Leontiev (2005) asserted that environment is not an external factor but a given object which "exists only in relation to a certain subject .... A given object becomes the environment only when it enters the reality of a subject's activity as an aspect of this reality" (p. 10). To a great extent, learners' motivation to learn drives them to interact with the environment and for this reason, learning can be understood as a process of child-motivation-environment (Siraj-Blatchford \& Clarke, 2001). Together, Altalo, Meier, and Frank (2017) argued that learners as subjects, environments as objects, and learning motivation as a driving force constitute the interconnected triad capable of creating a form of doing directed to learners' needs and interests. To understand this process is therefore to understand "how specific ways of engaging with the object are enabled or discouraged at the level of the activity system" (Edwards, 2005, p. 55). 


\section{Immigrant Children in Transition to Childcare}

The process of transitioning from home to a formal education and childcare setting is a product of two forces: the child's adaptation to a new learning environment and the environment's inclusion of a new child. For researchers, home-to-centre transition does not only involve learning about the new environment; children face many issues, in particular, separation and adaptation, readiness for learning, communication, inclusion, and making friends (Brooker, 2008; Dunlop \& Fabian 2007; Perry, Dockett, \& Petriwskyj, 2014). According to Tan (2011), "entering the school system is a life-changing experience for children" (p. 310), and according to Skouteris, Watson, and Lum (2012), it is "a daunting experience" (p. 78). Research suggests that the experiences and outcomes of children's educational transitions are closely related to inclusion and adjustment of the school or an early childhood learning environment (O'Farrell \& Hennessy, 2014; Perry et al., 2014). After a cross-country review of early childhood education and care settings in 20 countries, the Organisation for Economic Co-operation and Development (OECD; 2006, p. 64) reports that "transitions for children are critical occasions: they can be a stimulus to growth and development, but if too abrupt and handled without care, they carry — particularly for young children — this risk of regression and failure."

The issues of transitioning from homes to early childhood environments are even more evident with immigrant children due to the differences of languages, cultural practices, and life styles between their homes and the new environments (Crosnoe \& Ansari, 2016; Middlemiss, Crosnoe, \& Ansari, 2016). The scholarly framework for understanding the transition experiences of immigrant children in early childhood settings has been based on the following factors: (a) second language communication; (b) cultural influence and home language retention; (c) family involvement; (d) teacher support; and (e) peer relationship (Dyson, Qi, \& Wang, 2013). In general, past studies have found that immigrant children face many challenges during their transition to early childhood services; and these challenges include, most typically, communication difficulties, social exclusion, cultural unfamiliarity, and parent disengagement (Ebbeck, Yim, \& Lee, 2010; Jones, 2011; Vesely \& Ginsberg, 2011; Washbook, Waldfogel, Bradbury, Corak, \& Ghanghro, 2012).

Various scholars have suggested that educational environments, learning programs, and teachers can make a huge difference in immigrant children's transition from homes to early childhood settings (Matthews \& Mahoney, 2005; Sinkkonen \& Kyttala, 2014). Yet, the limited knowledge of teachers about immigrant children's needs and interests and a lack of participation of parents in children's learning programs somewhat limits the degree to which support could be established (Guo, 2015). Not only are children's family experiences and factors in early childhood settings important for further understanding immigrant children's transition, but so is the role of immigrant children in shaping their own learning and development.

A recent understanding of young immigrant children's learning experiences, such as was found in the work of Adair and Colegrove (2014), Guo and Dalli (2016), and Sime and Fox (2015), was essential for the development of a child-driven perspective of the topic. It is in the exploration of immigrant children's strategies, motivation, and peer culture that they have made a significant contribution. For Guo and Dalli (2016), the 
defining characteristic of a supportive environment for immigrant children was control of the environment by children, in that "children controlled the ways in which their actions had an effect on everyday situations" (p. 264). Facing a new and unfamiliar world creates the possibility of motivation and responsibility; and this drives immigrant children to explore the dimensions of their own capacity, thereby dealing with the socio-cultural differences in the new world. Sime and Fox (2015) argued that there is now sufficient evidence of learning strategies of young immigrant children to support the idea that it is not their needs but their motivation that we should focus on. Adair and Colegrove (2014) claimed that it is time to reconceptualize immigrant children's learning in the sense of agency, thereby intentionally creating an environment for children to influence how and what they learn.

Understanding immigrant children's transition within the framework of environment-transition-motivation sees the transitional experiences as dynamic, interactive, and collaborative. Rather than an external event, immigrant children's transition is embedded in their developmental trajectories toward creating their learning environments. Such a framework is closely related to Leontev's (2005) activity theory that emphasizes children as motived drivers of their learning activities.

\section{The Present Study}

This study aimed to address gaps in knowledge comparing immigrant children's experiences when starting in early childhood environments. In particular, the research explored the relationship between the learning outcomes of immigrant children and their learning environments. Through comparing three young immigrant children in three different early childhood settings during the time of their transition, the study aimed to shed light on the mutual influences between children and their environments on their transition from homes to early childhood settings. Immigrant children in this study refers to children whose parents were not New Zealand citizens at birth and who speak a language other than English at home. Given the complexities of the early childhood environments, difficulties for immigrant children to transition to early childhood education, and how important it is to understand immigrant children's motivation and capacities, immigrant children's transition to early childhood environments requires investigation.

\section{Sites and Participants}

The study involved three boys all aged around 3 years: Jamie, from a mainland Chinese immigrant family; Nathan, from a Taiwanese immigrant family; and Siraja, from a Sri Lankan immigrant family. (The children's names are pseudonyms.) They were all starting their early childhood experiences for the first time. The early childhood centres were also purposefully selected against two criteria: (a) they were full time services where children had continuous experiences; (b) they had an immigrant child starting at the service during the time of the study. Table 2 is a brief overview of the children and their early childhood centres. 
Table 2

Sites and Participants

\begin{tabular}{|c|c|c|c|}
\hline Child & Jamie & Nathan & Siraja \\
\hline Age & 3 years, 3 months & 3 years, 1 month & 3 years, 4 months \\
\hline Place of birth & $\begin{array}{l}\text { Born in New Zealand to } \\
\text { a mainland Chinese } \\
\text { immigrant family }\end{array}$ & $\begin{array}{l}\text { Born in New Zealand to a } \\
\text { Taiwanese family }\end{array}$ & $\begin{array}{l}\text { Born in Sir Lanka. } \\
\text { Immigrated to New } \\
\text { Zealand at age } 2\end{array}$ \\
\hline Family & $\begin{array}{l}\text { Father: piano teacher } \\
\text { Mother: full-time } \\
\text { university student } \\
\text { A younger sister } \\
\text { Mother came to the } \\
\text { parent interview. }\end{array}$ & $\begin{array}{l}\text { Mother: fulltime accountant } \\
\text { Two older brothers: } \\
\text { students } \\
\text { Mother came to the parent } \\
\text { interview. }\end{array}$ & $\begin{array}{l}\text { Mother: fulltime student } \\
\text { Father: house husband } \\
\text { Both parents came to } \\
\text { the parent and child } \\
\text { interviews. }\end{array}$ \\
\hline $\begin{array}{l}\text { Parent } \\
\text { description } \\
\text { of child }\end{array}$ & $\begin{array}{l}\text { Active and warm- } \\
\text { hearted }\end{array}$ & $\begin{array}{l}\text { Friendly, happy, and easy- } \\
\text { going }\end{array}$ & $\begin{array}{l}\text { Soft, happy, and very } \\
\text { good at thinking }\end{array}$ \\
\hline $\begin{array}{l}\text { Research } \\
\text { participation }\end{array}$ & $\begin{array}{l}\text { Jamie had many } \\
\text { interactions with the } \\
\text { researcher. He provided } \\
\text { much information }\end{array}$ & $\begin{array}{l}\text { During the interview and in } \\
\text { some informal } \\
\text { conversations, Nathan } \\
\text { talked. }\end{array}$ & $\begin{array}{l}\text { Very quiet and said very } \\
\text { little during the } \\
\text { interview. }\end{array}$ \\
\hline $\begin{array}{l}\text { Prior centre } \\
\text { attendance }\end{array}$ & 1 week & 1 day & 3 days \\
\hline $\begin{array}{l}\text { Centre } \\
\text { information }\end{array}$ & $\begin{array}{l}\text { Attended by } 25 \text { children } \\
\text { aged } 3-5 \text { years. } \\
\text { Jamie was the only child } \\
\text { of non-English speaking } \\
\text { background. }\end{array}$ & $\begin{array}{l}\text { Attended by } 35 \text { children of } \\
\text { whom } 8 \text { were Chinese. } \\
\text { The head teacher } \\
\text { described the centre as a } \\
\text { multicultural place. There } \\
\text { were many Chinese cultural } \\
\text { practices: Chinese words in } \\
\text { display, free use of the } \\
\text { Chinese language for } \\
\text { communications, and } \\
\text { Chinese food for tea. }\end{array}$ & $\begin{array}{l}\text { Attended by } 40 \text { children } \\
\text { (40\% ethnic minorities). } \\
\text { Siraja was the only Siri } \\
\text { Lankan child. } \\
\text { The centre director } \\
\text { claimed: "Multicultural } \\
\text { practice is very strong } \\
\text { here. Children play with } \\
\text { everyone. We have } \\
\text { teachers from different } \\
\text { cultures." }\end{array}$ \\
\hline Teachers & $\begin{array}{l}3 \text { full-time qualified } \\
\text { teachers and } 1 \text { part-time } \\
\text { teacher. All were } \\
\text { female, New Zealand } \\
\text { European. Teachers } \\
\text { had limited experiences } \\
\text { of working with children } \\
\text { and families of minority } \\
\text { cultures. }\end{array}$ & $\begin{array}{l}1 \text { teacher was Chinese and } \\
\text { the other } 5 \text { were New } \\
\text { Zealand European. All the } \\
\text { teachers were qualified and } \\
\text { had experience of working } \\
\text { with children and families of } \\
\text { minority cultures. The } \\
\text { Chinese teacher spoke } \\
\text { Chinese with Chinese } \\
\text { children. }\end{array}$ & $\begin{array}{l}\text { Teaching team is } \\
\text { multicultural: } 1 \text { Chinese, } \\
1 \text { Indian, } 1 \text { Samoan, } 1 \\
\text { Maori and } 3 \text { New } \\
\text { Zealand European. All } \\
\text { the teachers were } \\
\text { qualified and had } \\
\text { experience of working } \\
\text { with children and } \\
\text { families of minority } \\
\text { cultures. }\end{array}$ \\
\hline
\end{tabular}




\section{Study Design}

The design of the study involved a multi-perspective approach, which has been used successfully in other studies on children's transitions (O'Farrelly \& Hennessy, 2014; Warren, Vialle, \& Dixon, 2016). Data were collected through observations and interviews with each child, and individual interviews with each child's teacher and with each child's parent. These methods allowed access to multiple people, multiple perspectives, and multiple experiences in the children's learning environments. Observations of each child took place for 5 full days. The information recorded included "portraits of the subjects; reconstruction of dialogue; description of physical setting; accounts of particular events; depiction of activities; the observer's behaviour" (Bogdan \& Biklen, 2003, p. 113-114). In particular, I wrote down the social interactions in which each child participated, and play and learning activities the child engaged in. During the observations, I paid special attention to the children's use of language, the situations in which they spoke, and the people involved. I used pen and paper to record my observations and a cam video recorder to document scenarios.

A semi-structured individual interview with parents and teachers took place after the child observations. In total, four parents (three mothers and one father) and eight teachers participated in the interviews. Each parent or teacher interview was about an hour long. All the interviews followed a basic schedule of intended questions (see Appendices A and B). The interviews began with the background information about the participant, followed by a conversation in which the parent(s) or teacher told me about their experiences with the study child. In conversations with the parents, we talked about the child's experience in the family; and in those with teachers, we discussed the child's start in the centre. From these descriptions I asked further questions for clarification of their ideas, feelings, and understandings. At times, I interjected with alternative explanations to encourage insights from a broader perspective, for example, to say "I wonder if it is also because he was...." By introducing alternative viewpoints, I adopted a co-operative approach to seek meanings with the participants about what had been expressed (Tuckman \& Harper, 2012).

It was expected that the parents and teachers would provide new insights into the research topic, but these interviews also helped me answer specific questions that had arisen from the child observations. During the study, I also engaged in informal conversations in which I sought feedback for any emerging enquiries. I took opportunities to have conversations with the children, their parents, and teachers when I noticed emerging events or behaviours that I needed to clarify for further understanding.

In the interviews with Jamie and Nathan, we talked in Mandarin Chinese, our common home language; and with Siraja, his parents helped translate the languages. The process (see Appendix C) was supported by four stories constructed around four typical life experiences of children. The topics of these stories included: starting the day at the early childhood centre, free play time, playing with peers, and playing with a teacher (see Appendices). Using an imaginary child named Max, I told only the beginning of the story about Max in each topic and asked the child to continue in his own words. The child was also provided with pens and paper for drawing if he wanted. 
To conduct a rigorous data analysis, I engaged in an ongoing reflective practice of journaling from the commencement of the study. Data collection and analysis were performed simultaneously.

In practice, the process consisted of examining, categorizing, and thematically organizing the data. All the data were transcribed and then analyzed using a set of codes that reflected the five outcomes in Te Whäriki. This involved selecting and highlighting words, phrases, and learning and teaching episodes that corresponded to each learning outcome, for example, "well-being and trust." In order to avoid too much subjectivity in categorizing children's data to the learning outcomes, some teachers and parents were invited to the process of data analysis. Upon completion of the analysis for each individual child, a final analysis of patterns and themes was compared across the three children to identify common and different aspects of their learning experiences and learning environments.

\section{Three Immigrant Children in Transition to Early Childhood Centres}

To talk about the learning environments that address the children's experiences, I use the five learning outcomes of the framework introduced in Table 1. Analysis of the children's data identified several ways in which the children's learning experiences could be described in terms of the five learning outcomes; and some learning experiences were found to be unique to an individual child in a specific environment, while other learning experiences emerged as a pattern shared by all three children. Shared experiences included the children's positive attitudes toward the environment, teachers' care, free exploration, and limited teacher-parent interactions. Unique experiences involved peer collaborations, children's contributions, parents and teachers' different understandings of children's learning, and the inclusion of home cultural practice. In this section, I describe these findings in relation to each of the five learning outcomes in Te Whariki.

\section{Well-being and Trust: Children's Positive Attitudes to Settling and Teachers' Care for Them}

All three children held a positive attitude toward the childcare environment. For example, Jamie stated, "I like here. I want to play with other children." Jamie's parents had a vision for the kind of environment they wanted Jamie to be in, "We want Jamie to learn New Zealand culture because he cannot get that at home." According to his mother, Jamie was well aware that he must stay in the centre. Jamie was observed to willingly say "goodbye" to his father each morning and always appeared happy when arriving in the centre. In much the same way, Nathan and Siraja's parents were also positive about the new learning environment and said that "Nathan is happy here" (Nathan's mother) and "It is a nice place" (Siraja's mother).

Nathan's teachers were clearly aware of the importance of taking good care of Nathan. For example, Nathan's teacher Holly stated, "We focus on Nathan's well-being. We want him to enjoy here." Such an idea was also found in the statement of June, another teacher. She insisted that "we pay attention to Nathan and care about him." 
As noted by Siraja's teachers Abby and Zoe, providing a caring environment and engaging children in play were the particular focus of their learning programs. During the study with Siraja, he was observed to focus on getting to know the place, by walking, looking, and running around in the centre. Siraja aimed "to know here." The teachers, particularly Abby, an Indian teacher, were the first point of contact for Siraja. Abby was very responsive to Siraja. For example, Siraja approached her and took Abby to the sandpit when Siraja wanted a bucket. After realizing Siraja's needs, Abby quickly found a bucket. Siraja told me that "Abby is like auntie." His mother confirmed this idea and said, "Siraja told us that Abby looked like my sister, so he likes being with Abby." Abby was happy that she was like Siraja's aunt, so she was able to "build a close relationship with Siraja although we talk little because I [Abby] cannot speak Sinhala."

\section{Belonging and Purposeful Activity: Following Routines and Engaging with Peers}

During the study, Jamie was seen to freely explore the environment, and he was aware of the routines and rules. The teachers' opinion that Jamie knew what to do was confirmed by Jamie himself, who observed, "I just do what other children do." There were also observations of the ways in which Jamie was engaged in group activities, and this seemed to be supported by his teachers' focus on him. "We take good care of Jamie so to find out his needs." In much the same way, Jamie approached his teachers, particularly the head teacher, Nicki, when he needed help, for example when he wanted to change his soiled pants.

Nathan's teachers highlighted the importance for him of being included in the peer group in ways that suited his needs, so they assigned Lisa to pair up with Nathan. Lisa was a Chinese girl. She was 4 years old and had been in the centre for a year when Nathan started. Lisa spoke Chinese. Nathan's teacher Holly said, "We told Lisa to help Nathan."

With Lisa's help, Nathan was observed to quickly settle into a Chinese peer group. Chinese peer interactions were also identified as an explicit practice in the centre.

Nathan arrives in the centre. Lisa sees him and quickly leaves her play. She walks to Nathan, holding his hand and they two walk outside to the swinging where Kate and Shaun, two other children were playing. Lisa: "Nathan lai le [Nathan is joining us]." Kate: "Hi, Nathan." Shaun waves to Nathan.

For more than 16 minutes, Nathan stayed with the Chinese peers in the swinging area. They talked in Chinese and laughed. Nathan appeared very happy. They left the area when a teacher called them in for the morning group activity. When asked about what he liked to play, Nathan quickly said, "I like pushing Lisa on the swinging, and she pushes me, too."

With his teachers' support, Siraja participated in all the routines and large-group activities. He was seen to follow the centre rules, too, such as washing hands before a meal and taking shoes off when walking to the sandpit. Although Siraja played alone most of the time, on the third day of my study with him he was observed to run with Jong, a Cambodian boy. They were running, laughing, and occasionally yelling. As the study moved to the fourth and fifth days, Siraja's interaction with Jong featured more 
prominently in his data. It was apparent that with Hong as a play peer, Siraja started to build his sense of belonging in the centre.

\section{Contribution and Collaboration: Varied Learning Experience in Different Environments}

The three children had different experiences with peer collaborations and group contributions, and this seemed to be the result of the peer dynamic of the environments and also of whether they could access a peer of similar minority cultural background.

As Jamie explored the environment, he experienced challenges with social interactions. He made several attempts to initiate contacts with peers; and when these were rejected, he took aggressive actions. I recorded these observations:

Jamie walks around. He walks to a girl and gives her a cuddle. The girl pushes him away. Jamie hits the girl in the face.

Jamie repeated this behaviour in the following example:

Jamie stands by two boys who are putting together some puzzles. A boy stands up from his puzzle, looking for a piece. Jamie walks to the puzzle shelf and finds it. $\mathrm{He}$ hands the piece to the boy, who does not take it. Jamie gives him a nudge with the piece. The boy ignores him. Jamie throws the puzzle piece at the boy's face.

In this situation, Jamie meant to help, but the peer's neglect of his intention frustrated him. Jamie's attempts to help peers as a way of becoming included were obvious in his data. Disappointingly, the peers did not acknowledge Jamie's attempt to help. There is no doubt that Jamie was disappointed, which then rose to the level of anger so that he attacked his peers. In addition to hitting peers, Jamie sometimes released his anger by throwing toys around or destroying other children's work.

The teachers were not observed to help Jamie get to know his peers. Nicki was confident that "when Jamie's English gets better, he will be fine." She also said that "Jamie's collaboration with teachers helped him develop necessary social skills, such as listening and taking turns; and when Jamie's English is improved, he will transfer these skills to peer interactions." Jamie's parents were similarly understanding of some issues that Jamie experienced. His mother said, "The teachers have so many children to look after. The main thing is that Jamie is safe."

What was interesting in Nathan's data was his support for another Chinese peer, Wayne, who was 4 years, 6 months old at that time but quiet and withdrawn. I recorded the following:

Wayne is sucking his fingers behind the door of the block room. Nathan comes out of the block room. He sees Wayne. Nathan walks out to Wayne, reaching for Wayne's hand and leads him to the block room.

Later when the two boys went outside, Nathan took Wayne to the playhouse and after sitting down on the bench there, Nathan said to Wayne, "zuo dao zhe ba [let's sit here]," pointing to the space beside him for Wayne to sit. Nathan and Wayne played together for 46 minutes on that occasion, with Nathan playing the role of a carer. After that, Nathan was approached by Wayne, and they played together a few more times. It is 
very likely that the relationships that Nathan developed with Lisa and other Chinese peers contributed to his understanding of the reciprocal features of a peer friendship. In some sense, this example is representative of a friendship construction. Nathan developed a new peer relationship based on his experiences in other peer relationships.

During the study with Siraja, he played with Hong on a few occasions. He was not observed to engage with any other peers. The teachers included him in some group activities, but Siraja did not appear interested. When talking to the teachers about Siraja's start and his role in the group as a collaborative and contributing member, his teachers gave the following opinions of what was important in Siraja's learning:

What is important is that Siraja enjoys us. We take good care of them and make him happy. He will soon do everything other children do and be very active. (Amanda)

When a new child comes in, he is like a baby. It is important that we spend time with him. We cannot make any demands on Siraja. He is new and he doesn't know the language. He will be fine. (Abby)

Apparently, the teachers gave importance to Siraja's general well-being; and there was little recognition of how he could learn, collaborate, or contribute to the program. They seemed to have shared the idea that Siraja would eventually become an active member of the environment. Siraja's parents realized this and complained about the teachers "treating Siraja like a baby"; but they also said, "We understand it. It is hard for teachers because Siraja does not know English."

\section{Communicating and Representing: Home Language and English}

Both Jamie and Nathan made verbal communications in the centres using their home language or English. This was understood as the result of their access to speakers of both languages. For Sirjai, however, there was very little evidence related to his communication in any languages. Analysis of the data indicated the importance of people in the childcare environments who supported the children with their communications using the child's home language.

At Jamie's centre, he was the only person who could speak Chinese. Jamie made many attempts to speak Chinese with me and to stay around me. Even so, he was considered quiet both by his teachers and peers. His mother also understood Jamie's quietness as the result of his English difficulties, but Jamie explained this as "They don't know Chinese." Probably because of this, he was observed to copy some English words at a group time. Jamie said, "I think I need to learn English."

Nathan used Chinese in most of his communications. The availability of children of different cultures seemed to have created at the centre a very open space for communications in different languages. During my study with Nathan, I observed him using Chinese to ask Lisa for help in situations such as the one below:

Nathan is walking to Lisa: "wo ne xie zi tuo ba xia le [I cannot take off the shoes]."

Lisa: "wo Kankan [let me look]."

The buddy arrangement between Lisa and Nathan allowed Lisa to spend time with Nathan, which Nathan made good use of. Nathan knew very clearly that "I don't know 
English"; so during his start in an English-speaking environment, it was understandable that he relied on his home language to help his communication.

Coming to the early childhood centre, in both Nathan's mind and his mother's, was about learning English. Examples of Nathan's attempts to learn English were also found in his data. For example, he was observed to copy the teacher, saying single English words during a meal time.

Siraja was quiet in the centre. He was not seen to initiate communications with anyone. His mother was surprised, as "Siraja is very talkative and noisy." Siraja's teacher Amanda said, "There is nothing to be worried about Siraja's communication. All new children, including English speaking kids, could be quiet during their start. They are just cautious."

Unlike Siraja's teachers, his mother was very concerned about his learning of English: "I want him to speak fluently in English so he can properly settle in New Zealand." During the study with Siraja, the teachers were seen to try to teach Siraja some English words on eight occasions, for example, pointing to pictures and speaking slowly; but Siraja responded only twice, once through copying the teacher and once by nodding his head.

As the study progressed, it became obvious that Siraja involved himself most often in running outside or walking around. There were no data collected from him about his engagement with communication tools such as drawing, singing, dancing, or reading books.

\section{Exploring and Guided Participation: Learning in the Absence of Parents' Involvement}

Engaging children in free explorations was a preferred approach that teachers adopted across all the cases. Jamie's teacher Nicole said many times that the free learning environment in their centre could enable Jamie to learn and settle smoothly.

It seems that Jamie was expected to transition in the new environment mainly through his own exploration and teachers' attention to him. His father came to the centre each day. I never observed him talking to Jamie's teachers. They sometimes just said "hello" or "goodbye." Jamie's teacher Niki described the father's limited English as a barrier to communicating with him; therefore, "I do not talk to him." It was evident that no attempt was made by his teachers and parents to interact with each other, so Jamie's participation in the early childhood centre was not guided by the teachers' and parents' collaborations.

Cathy, Nathan's teacher, was very proud of the way in which "children are encouraged to find out what they want to do." There were resources of diverse cultures in the centre. Nathan could easily find Chinese books and Chinese music CDs, and he was observed to read a Chinese picture book with Lisa on one occasion.

Nathan's mother expressed a positive attitude toward Nathan's experience in the centre, as exemplified by the statement, "Nathan talks about Lisa and his Chinese friends. Although I don't talk to the teachers, I am happy that Nathan is doing well." In much the same way, Nathan's teacher Ellie was positive about Nathan's transition in the centre because "Lisa and all the other Chinese children are helping Nathan, although we haven't involved Nathan's mother in the process. She is hardly seen." 
Siraja's parents seemed busy each time they came to the centre. They were not observed to communicate with Siraja's teachers. Regarding Siraja's play with his peer Hong, his mother confirmed Siraja's explanation that he and Hong were playing lions because "Siraja likes animal games." The teachers did not realize that Siraja was engaged in a lion activity with Hong, but said "Siraja and Hong were just running around" (Abby). Although the teachers were trying to meet Siraja's needs and interests, because they didn't understand Siraja in the same way as the child and his parents did, Siraja did not appear interested in anything provided to him by the teachers. His father particularly criticized Siraja's learning in the centre as "baby things." His mother said, "Siraja is not learning anything. The teachers haven't attempted to teach."

\section{Looking Across the Children and Their Learning Environments}

Looking across the three cases, a number of ideas were identified that characterized the way young immigrant children experienced transitions from homes to Englishspeaking, early childhood environments. Leontev's point $(2005$, p.10) that "environment becomes the environment only when it enters the reality of a subject's activity" has theoretical interest for me. Building off scholarship in immigrant children's learning (Adair \& Colegrove, 2014; Ebbeck et al., 2010; Guo \& Dalli, 2016; Jones, 2011; Vesely \& Ginsberg, 2011), the five learning outcomes in Te Whāriki (Ministry of Education New Zealand, 1996), and socio-cultural perspectives (Rogoff, 2003; Vygotsky, 1978), I delineate four features of early childhood environments that are particularly valuable for children's learning: children's motivation to learn, home culture in practice, access to teacher attention and peer support, and children's free exploration in the environment. Figure 1 shows these contributing factors to children's positive learning outcomes.

\section{Figure 1. Contributing Factors to Positive Learning Outcomes}

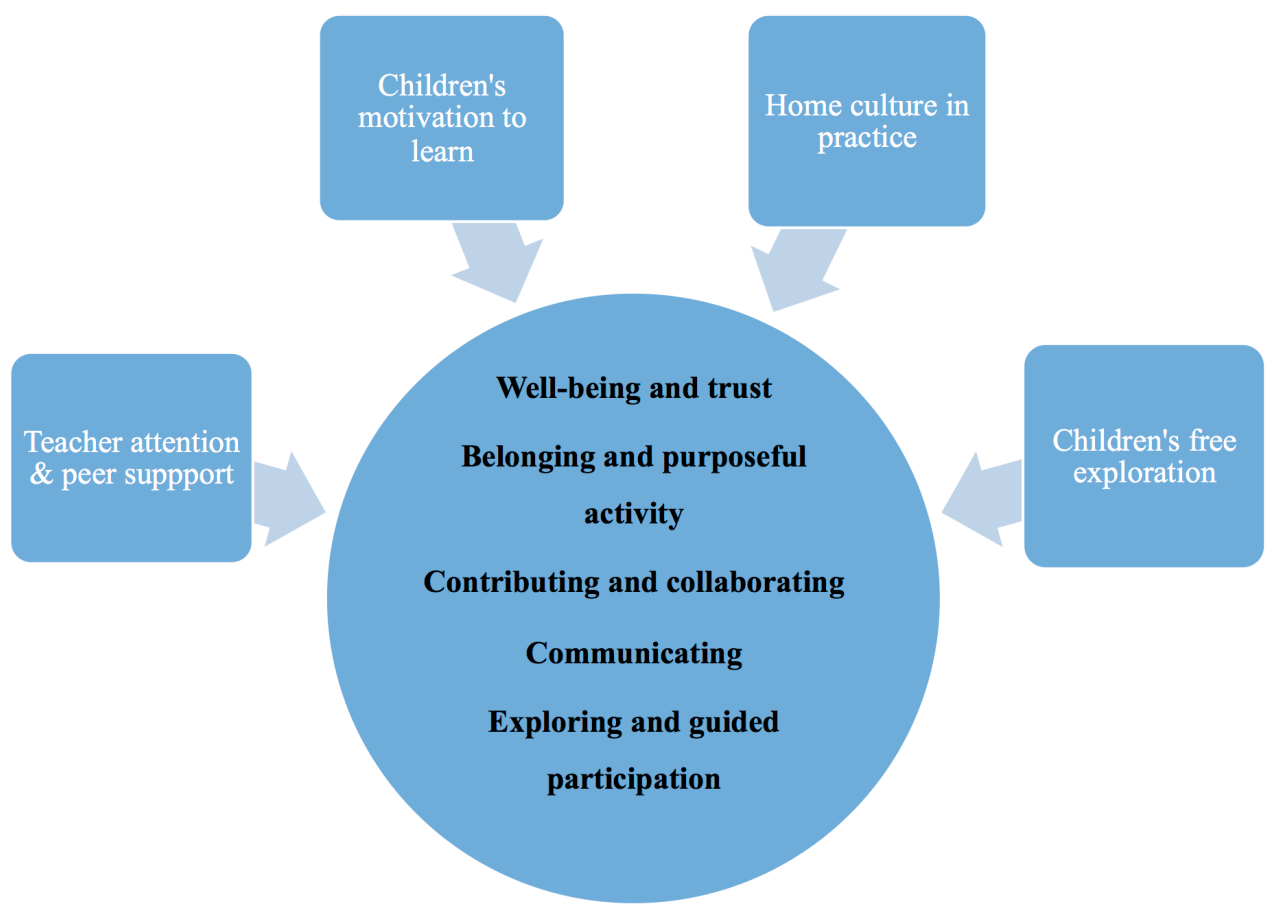




\section{Contributing Factors to Immigrant Children's Positive Learning Outcomes}

In many ways, children's motivation is the key to their learning. Attempts to make friends, to learn English, to follow routines and teacher instructions, and to participate in learning opportunities made up all the experiences. Much of what happened was a process of the children's motivation and their desire to settle in the setting because "I like here. I want to play with other children" (Jamie). The children's attempt to settle, which emphasized their motivation, is in fact an important idea in activity theory: that learners' motivation is the determiner of their learning (Leontev, 1997). It has been argued, too, that "learners' intent is a more compelling factor for action than the affordances of the environment" (Hargraves, 2014, p. 321). The contribution of young immigrant children's motivation to their learning outcomes has become a well documented finding in recent studies (Adair \& Colegrove, 2014; Guo \& Dalli, 2016; Sime \& Fox, 2015). The present research shows that the children's desire and motivation to settle in their early childhood environments have profound effects on their well-being, on their exploration of the environment, learning English, and making attempts to interact with people and things.

A consistent theme in Nathan's data was the positive influence of Chinese culture on his learning. The data from Jamie and Siraja also showed that home culture was employed to develop confidence and build collaborations in the new learning environment, thus nurturing children's well-being and a sense of belonging. For example, Jamie spoke Chinese with me and stayed around me because I was the only person in his centre who spoke Chinese. In a similar way, Siraja wanted to be with Abby because Abby was Indian who looked like Siraja's aunt. The study therefore bears out and extends previous research indicating that home culture or familiar people support effective learning outcomes of immigrant children, and that they influence actions and strategies such as exploring and understanding the environment (Bradley, Pennar, \& Glick, 2014;).

From a socio-cultural perspective, examples from the study show the strong influence of home cultures in supporting the children's transition from homes to the early childhood environments, for example, through the use of home language in their peer groups. It could be said here that peers scaffolded the children's learning of new cultural practices using tools of their original culture. A further aspect of the influence of home culture on the children's learning, which connects with socio-cultural accounts of children's development, particularly Rogoff's guided participation (2003), is the Chinese peer community in Nathan's learning environment. Scaffolding, a concept popularized by Vygotsky and a form of guided participation, became an essential part of Nathan's learning experience with his peers.

On the other hand, it was found that in Jamie's centre, where there was only one immigrant child attending, the home cultural practices that he would relate to for a sense of belonging and through which other children could gain an understanding, were lacking. Nobody in his centre could interpret his verbal communications, and thus his attempts to participate in the new environment were thwarted. While the study did not see his attending an English-only childcare centre as threatening Jamie's well-being, it was 
evident that in the absence of home cultural resources Jamie had difficulties building a sense of belonging (Bradley et al., 2014; Guo \& Dalli, 2016).

Previous research provides strong evidence of the importance of peer support in immigrant children's learning (Barron, 2009). Looking across the peer experiences of all the examples, I conceptualize peers of similar or other minority cultural communities as crucial in creating the initial social experiences for the immigrant children. Particularly in Nathan's example, his use of Chinese with Chinese peers, and the vital social bonds between them, highlight the contributions of familiarities and similarities to his smooth transitional experience. In much the same way - as exemplified by Jamie, who did not have Chinese or other minority cultural peers - supporting immigrant children's experiences with English-speaking peers is especially crucial. A significant issue that the present study highlighted is the difficulty he experienced in becoming engaged in peer relationships; and because of this, Jamie could not properly collaborate with the environment and make useful contributions. The findings of this study are thus consistent with previous studies in which peers supported children's transitions from homes to educational services (Adair \& Colegrove, 2014; Barron, 2009).

The value of free exploration in the children's learning outcomes is identified in all three cases; and this illustrates what Te Whāriki (Ministry of Education, New Zealand, 1996) describes as the learning outcome of contributing and collaborating, in which children "find out what they want to know and to understand their own ways of learning" (p. 64). In such an open environment where children were supported to play, they were undoubtedly happy to come and stay. This could have partially explained why Jamie appeared as settled as the other two children despite his communication and social challenges.

Parents are obviously major agents in immigrant children's learning (Adair \& Barraza, 2014; Bradley et al., 2014; Lea, 2012); but however important they are, it was found that the parents in this study chose to stay away. Analysis of the parents' comments made clear that they were understanding and gave priority to children's safety, despite the fact that they had opinions, such as that "teachers [should] teach Siraja English." The parents' attitudes and behaviours in the children's early childhood environments is scarcely surprising. It is this kind of attitude which Hamilton, Marshall, Rummens, Fenta, and Simich (2011) described as "passive" (p. 314). The parents' disengagement in their children's early childhood environment was supported by some teachers, too, as reflected in Nicki's view that "Jamie's father is difficult to understand, so I don't talk to him."

What is lost in the children's learning environments is therefore a collaborative relationship between their families and the early childhood settings. As Ali (2012, p. 197) reported, "Many teachers are White and middle-class women who have not had sustained or close contact with immigrant families, or sufficient preparation for working with them." Ebbeck et al. (2010) as well as Jones (2011) all pointed out that early childhood teachers and immigrant parents give primacy in their work with immigrant children not to partnerships but to individual responsibilities, such as what teachers and parents do with children in their separate environments. As a result, as Adair and Barraza (2014) commented, young immigrant children have to find ways of settling in their early childhood environments in the absence of family input. The present study provides a 
similarly disappointing model of learning environments in which there was no attempt from the adults to integrate children's experiences and create continuity between them.

Leontev's (2005) activity theory explains how learning processes are facilitated by all the richness and variety of socio-cultural forms. According to the teachers and parents in this study, their responsibilities do not necessarily focus on mutual interactions; whereas supporting children to develop New Zealand ways of living is necessary for children's learning. Without such support, although the children seemed settled in the new environment, their experiences might not be purposeful and meaningful, as seen in Siraja, who appeared disengaged.

There is also an explicit consensus in all the teachers' replies that paying attention to immigrant children is important. Terms such as care, trust, baby, needs, and safety were provided as reasons for teachers to pay attention to the children. In her study of teachers working with culturally diverse children, Keats (1997, p. 56) reported that "many [professionals] prefer to be able to deal only with the child, finding the parent from another culture difficult to understand." While my research supports this statement, the finding that the teachers had clear intentions to support the children through taking good care of them constitutes a useful empirical basis from which to investigate other influences on the complex relationship between teachers and immigrant parents. Given the short time frame of my observations, the purpose of which was only to look at the beginning experiences of each child, the current study did not directly address how parents' disengagement in early childhood education might affect children's learning; but the findings suggest a direction for potential future research.

\section{Conclusion and Future Research}

This study highlights the complex and multi-faceted nature of young immigrant children's transition to English-speaking early childhood environments by documenting the experiences of three different children in three different early childhood settings. My key argument has been that different people, places, and approaches to learning have interacted to create a particular site for each child's beginning experiences in the early childhood environments.

Socio-cultural theories provided a framework for understanding how the children and their environments interacted. The findings indicate that outcomes of young immigrant children's learning during their start in early childhood services are also related to their own motivation and their capacity to relate to other people, routines, and resources in the environments. The most satisfactory outcomes achieved could be seen with Nathan, who had Chinese cultural resources available to support him. The present findings can be regarded as evidence supporting the view that learning is a socio-cultural practice (Rogoff, 2003; Vygotsky, 1978). This also resembles Guo and Dalli's (2012) point that "[immigrant] children's experiences were strongly affected by their ability to use the cultural tools of their home culture - primarily language - to mediate their experiences in their new context" (p. 136).

Integrating children's motivation with their learning environments provides a strength-based understanding of children's learning. The key message of the study is that 
the examination of immigrant children's capacity and motivation, not just their needs, leads to meaningful knowledge about their experience in early childhood settings. Early childhood environments should open up possibilities for embracing and celebrating a child-driven and motivational approach to learning and for recognizing immigrant children's capacity to relate to people, places, and things.

Importantly, the cases in this study illuminate what Leontiev (1977) referred to as children's activity "in all the richness and variety of its forms" (p. 2), in the sense that learning is related to all their environments, including those beyond the early childhood settings. What is needed is the development of a strong relationship between early childhood centres and children's families. In making this point, I have been influenced by Lea's (2012, p. 105) finding about immigrant children's lack of motivation in school because "cultural conflicts sap their energy and cause identity problems." The present study points in the direction of longitudinal research on immigrant children's motivation. If young children are motivated to learn during their beginning experiences in early childhood settings, what might contribute to the maintenance or loss of their motivation in later stages of their learning? In relation to this, there is also a need to understand how immigrant parents' attitudes toward and behaviours in children's learning environments contribute to their children's learning outcomes in both the short and long terms.

\section{References}

Adair, J., \& Barraza, A. (2014). Voices of immigrant parents in preschool settings. Young Children, 69(4), 32-39.

Adair, J., \& Colegrove, K. (2014). Communal agency and social development: Examples from first grade classrooms serving children of immigrants. Asia-Pacific Journal of Research in Early Childhood Education, 8(2), 69-91.

Altalo, T., Meier, J., \& Frank, E. (2017). Information sharing on children's literacy learning in the transition from Swedish preschool to school. Journal of Research in Childhood Education, $31(2), 240-254$.

Ali, M. (2012). The shadow of colonialism on relations between immigrant parents and their children's teachers. Alberta Journal of Educational Research, 58(2), 198-215.

Barron, I. (2009) Illegitimate participation? A group of young minority ethnic children's experiences of early childhood education. Pedagogy, Culture \& Society 17(3), 341-354.

Bogdan, R., \& Biklen, S. (2003). Qualitative research for education: An introduction to theory and methods (4th ed.). Boston, MA: Allyn \& Bacon.

Bradley, R., Pennar, A., \& Glick, J. (2014). Home environments of infants from immigrant families in the United States: Findings from the new immigrant survey. Infant Mental Health Journal, $35(6), 565-579$.

Brooker, L. (2008). Supporting transitions in the early years. Maidenhead, UK: Open University Press.

Crosnoe, R., \& Ansari, A. (2016). Family socioeconomic status, immigration and children's transitions in school. Family Relations, 65(1), 73-84.

Dunlop, A., \& Fabian, H. (2007). Informing transitions in the early years: Research policy and practice. Maidenhead, UK: Open University Press. 
Guo

Dyson, L., Qi, J., \& Wang, M. (2013). At the interface of ethnicity and recent immigration: Family functioning of Chinese with school-age children in Canada. Journal of Child \& Family Studies, 22(8), 1061-1073.

Ebbeck, M., Yim, B., \& Lai, M. (2010). Belonging, being and becoming: Challenges for children in transition. Diaspora, Indigenous \& Minority Education, 4(2), 103-117.

Edwards, A. (2005). Let's go beyond community and practice: The many meanings of learning by participating. The Curriculum Journal, 16(1), 49-65.

Gunn, A. (2015). Research work as curriculum work in New Zealand early childhood settings: What should be taught and learned? Journal of Pedagogy, 6(2), 103-117.

Guo, K. (2015). Teacher knowledge, child interest and parent expectation: Factors influencing multicultural programs in an early childhood setting. Australasian Journal of Early Childhood, 40, 63-70.

Guo, K., \& Dalli, C. (2012). Negotiating and creating intercultural relations: Chinese immigrant children in New Zealand early childhood centres. Australasian Journal of Early Childhood, 37(3), 129-137.

Guo, K., \& Dalli, C. (2016). Belonging as a force of agency: An exploration of immigrant children's everyday life in early childhood settings. Global Studies of Childhood, 6(3), 254-267.

Hamilton, H., Marshall, L, Rummens, J., Fenta, H., \& Simich, L. (2011). Immigrant parents' perceptions of school environment and children's mental health and behaviour. Journal of School Health, 81(6), 313-319.

Hargraves, V. (2014). Complex possibilities: 'Working theories' as an outcome for the early childhood curriculum. Contemporary Issues in Early Childhood, 15(4), 319-328.

Jones, D. (2011). The lives and challenges of immigrant children in the United States: A descriptive study. International Journal of the Humanities, 9(10), 29-39.

Keats, D. (1997). Culture and the child: A guide for professionals in child care and development. Sussex, UK: John Wiley \& Sons Ltd.

Lea, M. (2012). Cooperation between migrant parents and teachers in school: A resource? CEPS Journal, 2(1), 105-124.

Leontiev, A. (1977). The development of mind. Moscow, Russia: Progress Publishers.

Leontiev, A. (2005) Study of the environments of the pedagogical works of L. S. Vygotsky, Journal of Russian and East European Psychology, 43(4), 8-28.

Matthews, L., \& Mahoney, A. (2005). Facilitating a smooth transitional process for immigrant Caribbean children: The role of teachers, social workers, and related professional staff. Journal of Ethnic \& Cultural Diversity in Social Work, 14(1/2), 69-92.

Middlemiss, W., Crosnoe, R., \& Ansari, A. (2016). Family socioeconomic status, immigration and children's transition to school. Family Relations, 65(1), 73-84.

Ministry of Education New Zealand. (1996). Te Whäriki: He Whariki Matauranga mo nga Mokopuna o Aotearoa: Early childhood curriculum. Wellington, New Zealand: Learning Media.

Nuttall, J. (Ed.). (2013). Weaving Te Whāriki: Aotearoa New Zealand early childhood curriculum framework in theory and practice. Wellington, New Zealand: NZCER Press.

O'Farrell, C., \& Hennessy, E. (2014). Watching transitions unfold: A mixed-method study of transitions within early childhood care and education settings. Early Years: An International Research Journal, 34(4), 329-347. 
Office of Ethnic Communities. (2016). Culture and identity in New Zealand. Retrieved from http://ethniccommunities.govt.nz/story/culture-and-identity-new-zealand

Organisation for Economic Co-operation and Development. (2006). Starting strong II: Early childhood education and care. Paris, France: Author.

Perry, B., Dockett, S., \& Petriwskyj, A. (2014). Transitions to school: International research policy and practice. London, UK: Springer.

Rogoff, B. (2003). The cultural nature of human development. New York, NY: Oxford University Press.

Sime, D., \& Fox, R. (2015). Migrant children, social capital and access to services post-migration: Transitions negotiation and complex agencies. Children \& Society, 29(6), 524-534.

Sinkkonen, H., \& Kyttala, M. (2014). Experiences of Finnish teachers working with immigrant students. European Journal of Special Needs Education, 29(2), 167-183.

Siraj-Blatchford, I., \& Clark, P. (2001). Supporting identity, diversity and language in the early years. Buckingham, UK: Open University Press.

Skouteris, H., Watson, B., \& Lum, J. (2012). Preschool children's transition to formal schooling: The importance of collaboration between teachers, parents and children. Australasian Journal of Early Childhood, 37(4), 78-85.

Tan, S. (2011). The bridge: A group for Chinese immigrant parents transitioning their children to an American preschool. Social Work with Groups, 34, 310-319.

Tuckman, B., \& Harper, B. (2012). Conducting educational research. Lanham, MD: Rowman \& Littlefield Publishers.

Vesely, C., \& Ginsberg, M. (2011). Strategies and practices for working with immigrant families in early education programs. Young Children, 66(1), 84-89.

Vygotsky, L. S. (1978). Mind in society: The development of higher psychological processes. Cambridge, MA: Harvard University Press.

Warren, J., Vialle, W., \& Dixon, R. (2016). Transition of children with disabilities into early childhood education and care centres. Australasian Journal of Early Childhood, 2(18), 18-26.

Washbook, E., Waldfogel, J., Bradbury, B., Corak, M., \& Ghanghro, A. (2012). The development of young children of immigrants in Australia, Canada, the United Kingdom and the United States. Child Development, 83(5), 1591-1607.

\section{Authors' Note}

Correspondence concerning this article should be addressed to Karen Guo, Melbourne Burwood Campus, Deakin University, Victoria, 3125, Australia. Email: karen.guo@deakin.edu.au 


\section{Appendix A}

\section{Teachers' Interview Schedule}

1. Background of the teacher

- How long have you been working in this centre?

- How long have you been involved in early childhood education?

- What formal early childhood qualifications do you have?

2. What are the general expectations of immigrant children's learning experiences here?

3. Centre's teaching approach with immigrant children

- What are the typical ways of immigrant children starting childcare with you?

- Have you ever encountered difficulties when working with immigrant children during their transition? If so, what were they?

- What factors contribute to successful settlement of immigrant children?

4. The learning experiences of the studied child

- How has the child been doing so far?

- Are there any particular activities that the child is interested in?

- Has [child's name] made friends? Have you noticed how he usually behaves in groups?

- How do you feel about the child's communication?

- Can you describe the child's settlement process so far?

- How have you been supporting the child?

5. Parents' involvement

- Do the child's parents get involved, in your centre's experience so far? If so, how?

- Have you ever talked with parents about their ideas of their child's settlement? If so, when and how often?

- What have you been doing to help the parents participate in the child's learning? 


\section{Appendix B}

\section{Parents' Interview Schedule}

1. Background information of the parent

- Can I know some information about your education, profession, family structure, and opinions of your immigration experiences so far?

2. Background information of the child

- How would you describe [child's name]—such as his strengths and interests?

- Can you describe the learning process of your child over the past years?

- Does your child have any special needs?

2. The child's settlement in the centre

- What do you think about your child's learning experience so far?

- Has your child changed in any way after coming here? If so, in what ways?

- How does your child understand being at a place out of home like this?

3. General impression of the centre

- What opinions do you have about the teachers here in terms of their work with your child so far?

- Do you think an environment like this centre helps a lot with your child's settlement?

4. Parent involvement in the centre

- Have you learned about the teaching approaches here?

- Do you express your concerns about your child to the teachers here? If so, how?

- Have teachers informed you of your child's experience in the centre and asked you for your opinion? If so, how?

- Are there any specific things in your child's centre that concern you?

5. Parent expectations

- In what way do you think children settle and learn here?

- What in particular do you want your child to learn or develop at this centre? 


\section{Appendix C}

\section{Children's Interview Schedule}

The interviews with each child are conducted using pictures and some story beginnings. The procedures followed in conducting these interviews are:

1. Approach the child

2. Play with the child

3. Tell the child "Let me tell you a story about Max" (the child in the pictures; see Figure C-1). Show each picture for one minute, then narrate the standard story beginning.

4. Ask the child to continue the story.

The pictures (Figure C-1) display the scenarios reflecting the child's learning experiences. These story beginnings include:

1. Going to childcare

2. Free play

3. Playing with peers

4. Playing with a teacher/teachers

Fig C-1. Story Prompts

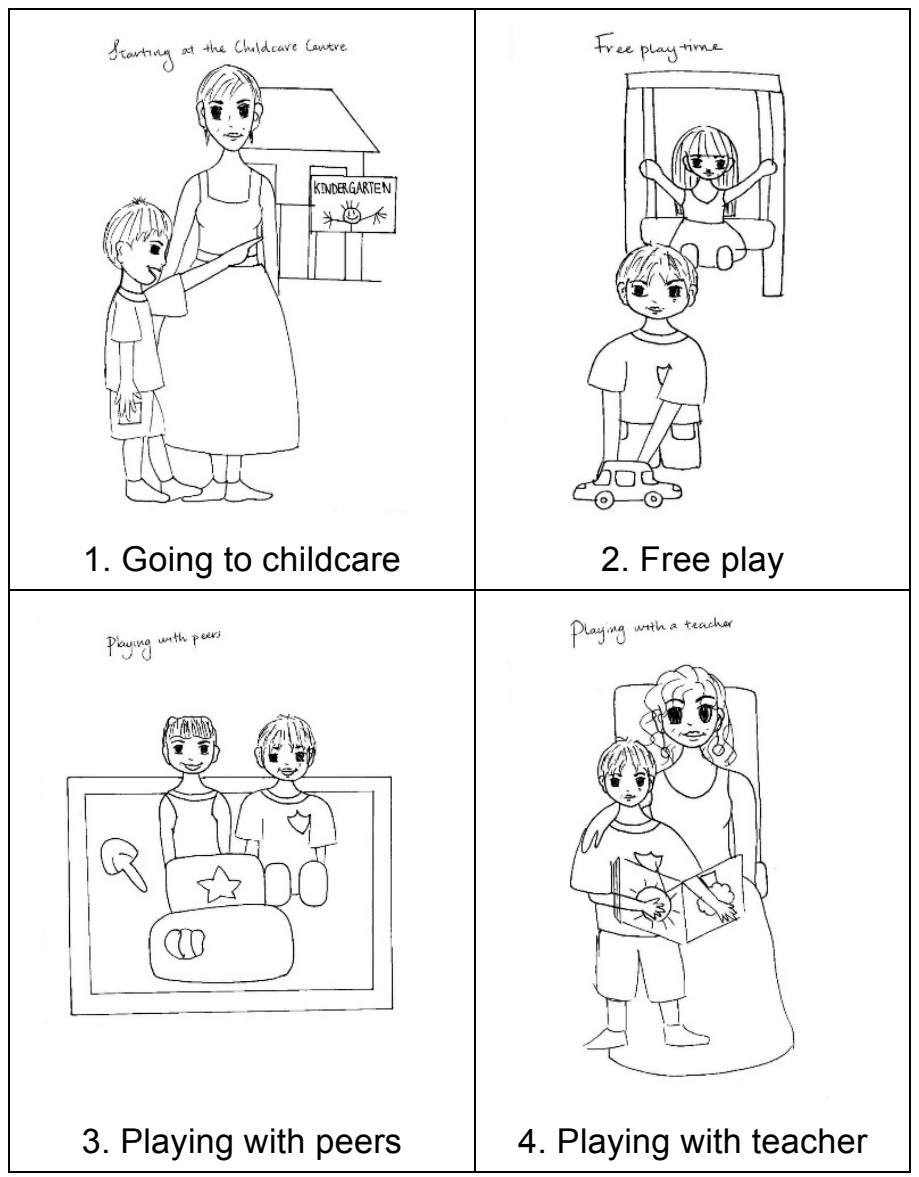

